\title{
Decision-making at the sharp end: a survey of literature related to decision-making in humanitarian contexts
}

\author{
Paul Knox Clarke ${ }^{1 *}$ and Leah Campbell ${ }^{2}$
}

\begin{abstract}
In a humanitarian response, leaders are often tasked with making large numbers of decisions, many of which have significant consequences, in situations of urgency and uncertainty. These conditions have an impact on the decision-maker (causing stress, for example) and subsequently on how decisions get made. Evaluations of humanitarian action suggest that decision-making is an area of weakness in many operations. There are examples of important decisions being missed and of decision-making processes that are slow and ad hoc. As part of a research process to address these challenges, this article considers literature from the humanitarian and emergency management sectors that relates to decision-making. It outlines what the literature tells us about the nature of the decisions that leaders at the country level are taking during humanitarian operations, and the circumstances under which these decisions are taken. It then considers the potential application of two different types of decision-making process in these contexts: rational/analytical decision-making and naturalistic decisionmaking. The article concludes with broad hypotheses that can be drawn from the literature and with the recommendation that these be further tested by academics with an interest in the topic.
\end{abstract}

Keywords: Decision-making, Leadership, Complexity, Uncertainty

\section{Introduction}

Decision-making lies at the core of any humanitarian response. An effective response requires a series of decisions: on whether and where to intervene, on the scale and nature of the intervention, and on how to best allocate resources, coordinate with other agencies, and maintain the safety and security of affected people and of humanitarian staff.

Given the importance of decision-making, it is sobering to observe how critical evaluations are of the ability of humanitarian leaders to make decisions. Decision-making is often slow (Adams et al. 2015; Agulhas Applied Knowledge 2015; Murray et al. 2015; Quasmi 2015; Sanderson et al. 2015; UNICEF 2015; Darcy 2016a); disassociated

\footnotetext{
* Correspondence: pknoxclarke@gmail.com

${ }^{1}$ Centre for Development and Emergency Practice, Oxford Brookes University, Gipsy Lane Campus, Oxford OX3 OBP, UK

Full list of author information is available at the end of the article
}

from strategy (Hayles 2010); opaque (Murray et al. 2015; Ambroso et al. 2016); and unaccountable (Agulhas Applied Knowledge 2015; Clarke et al. 2015; Darcy 2016b). Overall, humanitarian decision-making has been characterised as 'informal, emergent, ad-hoc and reactive' (Comes 2016: 2, see also Maxwell et al. 2013).

Despite these reported failures, relatively little academic attention has been given to decision-making in humanitarian response. Much of the work that does exist points to gaps in understanding: lack of knowledge about what decisions are made, by whom and how (Hayles 2010; Maxwell et al. 2013; Heyse 2013). Beyond this, the majority of academic attention has tended to focus on a small number of specific areas, particularly supply chain and logistics (e.g. Gutjahr and Nolz 2010; Yu and Lai 2011; Villa 2019) and the quality and use of information in decisions (e.g. Bradt 2009; Darcy et al.

\section{Springer Open}

(0) The Author(s). 2020 Open Access This article is licensed under a Creative Commons Attribution 4.0 International License, which permits use, sharing, adaptation, distribution and reproduction in any medium or format, as long as you give appropriate credit to the original author(s) and the source, provide a link to the Creative Commons licence, and indicate if changes were made. The images or other third party material in this article are included in the article's Creative Commons licence, unless indicated otherwise in a credit line to the material. If material is not included in the article's Creative Commons licence and your intended use is not permitted by statutory regulation or exceeds the permitted use, you will need to obtain permission directly from the copyright holder. To view a copy of this licence, visit http://creativecommons.org/licenses/by/4.0/. 
2013; Gralla et al. 2013; Gerdin at al. 2014; Knox Clarke and Darcy 2014; Colombo and Checchi 2018).

In this, as in other areas, humanitarian response lags behind other emergency response contexts. There is a rich literature on decision-making in emergencies, particularly as it relates to fire services, civil defence, and hazardous environments such as oil rigs. While these organisations differ from many humanitarian organisations in respect of their structures and culture, ${ }^{1}$ the review demonstrated that the types of decisions that they make, and the context in which these decisions are made, are similar to humanitarian contexts and dilemmas, allowing the possibility of learning from their experience.

Given the importance of decision-making for humanitarian response, the recognised gaps in existing understanding, and the relative wealth of knowledge on this topic outside the humanitarian response literature, this survey serves as a first step in a research programme aimed at making concrete improvements in the decision-making capacities of individuals and groups working in humanitarian responses-outlining what has already been recorded in the literature and identifying areas that require further study if improvements are to be made. To do this, it considers existing research around the context, challenges, and opportunities related to humanitarian decision-making by individuals at the operational level and explores two approaches to decision-making that are often discussed in the literature and that may be appropriate in these contexts. On the basis of a survey of the literature, it makes tentative hypotheses that can be tested through primary research and points to gaps in understanding where further research is needed.

\section{Methodology}

This article is based on a survey of academic and 'grey' literature. In the first instance, documents were identified via Google Scholar, using the search rubric: 'decision-making humanitarian OR emergency OR disaster', with the top 150 results reviewed for inclusion. The decision to use Google Scholar was based on the comparative advantages of this database for research in the social sciences (Herzing and van der Wal 2008). Documents were then included/excluded from the survey on the following basis: Documents about decision-making in a crisis environment where lives were at stake were included. Documents about decision-making in crises that did not result in mortality (i.e. in business) were excluded. Documents which dealt with provision of aid to a large number of people were included, whereas decision-making

${ }^{1}$ It is, of course, the case that humanitarian organisations also differ significantly from one another in terms of the way they make decisions (Heyse 2007) about a specific individual (generally a patient) was excluded. Finally, documents which looked at operational decision-making (for example, whether to conduct a specific action in a crisis, what to do, and where) were included whereas strategic/global policy decision-making (around the governance of an organisation or setting up a global network, for example) were excluded. After consideration against these criteria, 74 documents were initially selected for review. In a further step, the researchers decided to consider only a limited number of documents related specifically to operations management and the use of scientific models to support decision-making in logistics and supply chain management. This was because the initial list contained 40 documents of this nature, including three reviews of operations management literature related to emergency response, and the researchers felt that a heavy concentration on this particular type of decision and set of methods would not support the goal of the research (finding approaches that individual humanitarian decision-makers could make to improve the quality of their decisions). The researchers included five of these operations management documents in the survey.

Ultimately, 39 of the 150 documents identified by Google Scholar were included in the survey. In addition, the researchers contacted five experts in the field asking for recommendations, and this led to the inclusion of another 10 documents in the survey. A further 30 documents were considered that had been identified from the bibliographies of documents sourced through databases and experts. The authors also examined 40 recent evaluations of humanitarian action (from 2015 to 2017) that were selected as a purposive sample to provide an approximate reflection of the overall global distribution of humanitarian responses, and of the organisations that respond. Three hundred sixty-nine individual decisions were mentioned in these evaluations. In total, 79 documents and a further 40 evaluations were included in the survey. Of the 79 documents, 32 were related to the formal humanitarian system ${ }^{2}$.

The documents were coded using MaxQDA software. The authors used a broadly inductive approach (Bandara et al. 2015) to coding. Initial codes were established on the basis of topics of interest to the research. These were 'what are decisions about', 'conditions under which decisions are made', 'effects of these conditions on decision processes', 'decision processes used', factors contributing to successful decisions', and 'factors contributing to unsuccessful decisions'. Additional codes and sub codes were then added inductively.

The authors reviewed the coded segments to form an outline for the paper's arguments. Points which are

${ }^{2}$ As defined by ALNAP in the State of the Humanitarian System, 2018 
noted in this paper were highlighted across a number of sources. Where these points were contested in the literature, the alternative arguments are also included.

\section{Limitations}

The survey of the literature is not a systematic review. As such, it is not complete or exhaustive, and there will be evidence that relates to the topic which has not been considered in this article. Nor has the research or grey literature included in the review been assessed as part of this survey for evidential quality: arguments and conclusions outlined in this paper are based on recurrence and triangulation, rather than on assessment of the quality of individual source documents.

The survey was also restricted to documents available in the English language.

Finally, the survey-and particularly the review of evaluations-was unable to identify many detailed descriptions of the decision-making processes used in humanitarian operations. Evaluations-and the humanitarian literature more generally-tended to provide general descriptions of the situations in which decisions were taken and of the outcomes of decisions, without detailing how these decisions were actually made. This limits the degree to which the researchers can draw definitive conclusions on how humanitarians are currently working and on the strengths and weaknesses of decision-making approaches as they are used in the humanitarian context.

\section{The content and context of humanitarian decision-making} What are humanitarians making decisions about?

The review of humanitarian evaluations suggests that humanitarians working at the country level are making decisions across a wide variety of topics. Six main areas were addressed by decision-makers in the evaluations: whether to begin, end, scale up, or scale down responses; the type of response required (response options); who should receive assistance (targeting); how to ensure the right number of staff with the rights skills were involved in the response and how to manage the performance of these staff (staffing); whether to gather additional information, how to gather and analyse it and whether to share the information (information); and whether and how to work with other organisations (partnership). ${ }^{3}$ Other reviews of humanitarian action-while providing more detailed breakdowns of the type of decisions required under each area-generally confirm these as the

\footnotetext{
${ }^{3}$ This list does not include a number of elements that one might expect to see, particularly decisions about security conditions. This is because security was generally identified as a factor that was taken into consideration when making the decisions, rather than the focus of the decision itself.
}

main decision areas (Clements and Thompson 2009; Gralla et al. 2013; Huber and Jennings 2018). However, the literature also points up a seventh, arguably separate area of decision-making related to logistics and the supply chain (decisions, for example, around where to site facilities, the quantity of supplies to preposition, and how to plan routes to ensure the most effective distributions). This area is a particular focus of operations management scholars (Gutjahr and Nolz 2010; RodriguezEspindola et al. 2018; Villa et al. 2019).

Emergency management professionals (in, for example, the fire service and the coastguard) also regularly make decisions in all seven of these areas (see for example, Flin et al. 1998; Howitt and Leonard 2009; Kapucu and Garayev 2011; Rodriguez-Espindola et al. 2018).

The literature considered in this survey did not allow any judgement on the frequency of these different areas of decision in humanitarian response. The degree to which certain types of decision are considered may be as much a reflection of the interests of academics as the realities of humanitarian operations-and it appears possible that decisions about response options-a particular concern of researchers looking at the use of evidence in humanitarian action (Bradt 2009; Maxwell et al. 2013; Colombo and Checchi 2018) and logistics-may be overrepresented in the literature as a proportion of all decisions made. Certainly, the majority of the evaluations showed individuals or groups of decision-makers making decisions on all of the six areas over the period evaluated.

\section{The context in which humanitarian decisions are made}

The majority of the documents on humanitarian action considered in the survey made the point that humanitarian decision-makers work in challenging contexts-they are required to 'make hard decisions under pressure and with minimal information' (Colombo and Checchi 2018). The significance of the decisions that have to be made (Cosgrave 1996; Hayles 2010; Metcalfe et al. 2011), lack of information on which to base these decisions (Hobbs et al. 2012; Ortuño et al. 2013; Colombo and Checchi 2018), consequent uncertainty (Benini 1997; Kruke and Olsen 2012; Ortuño et al. 2013), and lack of time in which to make decisions (Cosgrave 1996; Hayles 2010; Comes 2016) are regularly cited as conditions that are prevalent in the humanitarian context, and which have a strong influence on the way in which decisions are made. Only a few authors mention explicitly that these conditions are not general to all emergencies (Ortuño et al. 2013) or may differ from one 'phase' of an emergency to another (Comes 2016). Researchers working in the field of emergency management give very similar descriptions of the contexts within which 'blue light' services and other emergency management professionals 
work: decisions are made in situations that are complex, uncertain, and time constrained; where there are many (often poorly coordinated) response actors; and where the stakes are extremely high ${ }^{4}$. In this section, we consider these specific elements of the humanitarian and emergency management contexts, and the ways in which they affect the decision-maker.

\section{A large number of decisions with significant consequences}

Many of the decisions which need to be made during a humanitarian crisis have very significant consequences (Cosgrave 1996; Hayles 2010). The potential significance of these decisions is increased both by the volatility of contexts where humanitarian action takes place and by the lifesaving nature of humanitarian response (Cosgrave 1996), conditions which are also found in other types of emergency response work (Weick 1993; Yu and Lai 2011). Research in the field of emergency management has noted the long-lasting impact that decisions taken in the early stages of response can have (Kowlaski-Trakofler and Vaught 2003). Not making a decision, or not making it quickly enough for timely action, can also have significant and negative long-term consequences (ibid).

Humanitarian decision-makers working in such an environment need to consider the potentially negative outcomes of their decisions for crisis-affected people, for humanitarian organisations, or for their staff (Metcalfe et al. 2011) Many of these potential consequences are extremely difficult to quantify in terms of their probability and severity, causing massive uncertainty for the decision-maker (Hobbs et al. 2012). Nevertheless, as in other emergencies, humanitarian decision-makers may be expected to find a way to weigh up their consequences (White and Turoff 2010) and make a decision.

\section{Urgent time pressures}

In humanitarian response, delay can be a matter of life and death. Humanitarian decision-making is often undertaken under immense time pressure (Cosgrave 1996; Zhang et al. 2002; Heyse 2007; UNICEF 2015; Oxford Policy Management 2016) as it is in emergency management situations (Mendonca et al. 2001; Yu and Lai 2011; Kapucu and Garayev 2011). This sense of urgency calls for what Leigh (2016: 5) describes as 'fast and frugal decision-making', where leaders are asked to

\footnotetext{
${ }^{4}$ Observers and academics considering emergency management in 'blue light' services frequently highlight the importance of complexity, uncertainty, and time constraints in decision-making (see for example, Danielsson and Ohlsson 1999, Kapucu and Garayev 2011, Yu and Lai 2011, Allen and Pearman 2015, Lu 2017) as well as the challenges of making decisions in multi actor environments (see: White and Turoff 2010, Kapucu and Garayev 2011, Rodriguez and Espindola 2018) and in conditions where the consequences will be extremely significant (Kapucu and Garayev 2011, Rodriguez and Espindola 2018).
}

think and act in ways they would not normally (Hayles 2010). This can include making decisions with 'partial or incomplete information' (Yu and Lai 2011: 207, see also Darcy 2016b) and 'before completely understanding the problem they face' (Gralla et al. 2016: 22).

The literature suggests that time pressure affects humanitarian decision-making in two ways. Firstly, it can affect the overall decision-making approach, generally by decreasing the number of people involved in the decision. Under circumstances of time pressure, humanitarian leaders are less likely to involve disaster-affected communities in processes of participatory decision-making (Adams et al. 2015). In Haiti, for example, the British Red Cross chose to work with existing civil society groups and rely on the assumption that these groups were representative of the community, rather than identifying other potential options for community engagement which would have taken more time (Advisem Services Inc. 2016). Humanitarian leaders are also less likely, when experiencing time pressure, to consult with colleagues, as they tend to assume that group decision-making will take longer (Cosgrave 1996; Knox Clarke 2014).

The second way in which time pressure influences decision-making is at the level of the individual's cognitive processes. Work with people working in emergency conditions suggests that where decision-making is urgent, less time is available to process information (White and Turoff 2010). Staff involved in the Syria response describe the impact of time pressure as causing a lack of brain space' (Agulhas Applied Knowledge 2015: 8). As a result, decision-makers are likely to consider a smaller number of decision options (Hidalgo et al. 2015; Advisem Services Inc. 2016; Lawday et al. 2016). They are also more likely to rely on mental 'shortcuts' such as heuristics and biases (Comes 2016; Gralla et al. 2016. For this effect in emergency management contexts, see White and Turoff 2010; Leigh 2016). These shortcuts 'reduce the mental effort and time required for problem solving' (Gralla et al. 2016: 23).

Not all humanitarian contexts are urgent, of course. Many of the crises humanitarians respond to are slow onset or protracted-and even sudden onset crises reach a period where the pace becomes more consistent. Urgency varies between each response (Ortuño et al. 2013) and even within the same response. This suggests that effective humanitarian decision-makers need not only to be able to make decisions under time pressure, but also to work effectively in situations were more time is available.

\section{Uncertainty about the current and future situation}

Many of the documents included in the survey argue that humanitarian crises are by their nature uncertainthey are dynamic, complex, unpredictable, and unstable (Benini 1997; Besiou et al. 2011; Metcalfe et al. 2011; 
Hobbs et al. 2012; Kruke and Olsen 2012). Uncertainty in a crisis environment can be defined as 'a sense of doubt that blocks or delays action' (Lipshitz et al. 2001: 337 ) and can manifest in various ways. Some typologies have identified up to 19 different kinds of uncertainty (see for example Benini 1997; Lipshitz et al. 2001; Klein 2009). Overall, in conducting the survey, the researchers identified two general categories: uncertainty about the current situation (when it is not clear what is happening now) and uncertainty about the future situation (when it is not clear what is going to happen in terms of either how an event will unfold or what the consequences of actions will be).

Uncertainty about the current situation in humanitarian contexts was generally related to a lack of information-which in turn relates to the availability, reliability, or relevance of information (Danielsson and Ohlsson 1999, see also Knox Clarke and Darcy 2014). Much of the humanitarian literature focuses on information availability-suggesting that too little information is available for humanitarian leaders (King 2005; Darcy et al. 2013; Knox Clarke and Darcy 2014; Van De Walle and Comes 2015) or that information exists but is not easily accessible or shared for a variety of reasons including security, competition between agencies, and incompatible information management structures (Zhang et al. 2002; Van De Walle and Comes 2015).

The quality of information is also a persistent problem (Cosgrave 1996; Benini 1997; King 2005; Knox Clarke and Darcy 2014; Van De Walle and Comes 2015; Colombo and Checchi 2018), and even where good quality information is available, it is not always relevant to the specific decision which needs to be made (Zhang et al. 2002) as each decision made by each decisionmaker at each organisation will require different information (King 2005; Gralla et al. 2013). Information will also become out of date (and therefore irrelevant) as the situation changes (Zhang et al. 2002; Hobbs et al. 2012; Obrecht and Bourne 2018): a problem compounded in the humanitarian sector by weak monitoring systems (Knox Clarke and Darcy 2014; Knox Clarke and Campbell 2015).

The second broad type of uncertainty relates to the future-how the situation will develop and what the possible consequences of actions might be (Hobbs et al. 2012). Sometimes this, too, is due to lack of information-perhaps because evidence of what will work does not exist or is not accessible to the decision-maker (Hayles 2010; Knox Clarke and Darcy 2014). However, the literature also suggests that the problem can be failing to focus on the right type of information, particularly where the situation is dynamic and unpredictable. In these circumstances, it seems to be less useful (beyond a certain level) to have information that will help the decision maker identify an action to take than to have feedback-information on the consequences of the actions that have already been taken (Mendonca et al. 2001; Kowlaski-Trakofler and Vaught 2003; Lu 2017).

To better understand why this might be the case, it is helpful to clarify the difference between uncertainty and risk-because the literature suggests that these two conditions call for different approaches to decision-making and because much evidence-based decision-making works appears to work better in situations of risk than in situations of uncertainty.

The term 'risk' is often used in humanitarian literature as a synonym for 'negative consequences'-humanitarian decisions described as 'risky' (see for example Metcalfe et al. 2011). This use of the term is misleading; however, as it blurs the distinction between risk and uncertainty, a distinction that hinges on how certain we can be that a decision will have negative consequences (Sitkin and Weingarten 1995; Metcalfe et al. 2011). Risk is the chance of an event occurring and the potential impact if it does. One much-used explanation is that risk = probability $\mathrm{x}$ impact ${ }^{5}$, where both probability and impact can be meaningfully quantified. For example, insurance companies assess the likelihood and possible impact of a driver having an accident in order to quote a price to provide that driver with car insurance and are able to do this because they have enough information about the probability of a certain type of driver (female, academic, in her 40s, driving mainly at the weekends) having an accident, and the cost of repairing that accident for her type of car. A 'risky' situation, then, is one where there is a potential for negative consequences, and where we can use information to quantify how likely the event is, and how negative the consequences will be.

However, not all events or possible outcomes can be assessed in terms of their likelihood and outcome. Many humanitarian situations involve a situation referred to in the literature as 'deep uncertainty' (Lee et al. 2012; Kalra et al. 2014). Humanitarian crises are complex environments. They involve multiple actors and variables which change, interact, and affect one another, creating so many potential future scenarios that it is impossible to predict and describe them all; however, much information is made available ( $\mathrm{Lu} \mathrm{2017).} \mathrm{When} \mathrm{dealing} \mathrm{with} \mathrm{the}$ outbreak of conflict in an urban environment, for example, it would not be possible to identify or 'model' the probability of all the different possible events, or the consequences of these events for the civilian population. And this, in turn, means that it is not possible to make a

\footnotetext{
${ }^{5} \mathrm{~A}$ humanitarian equivalent of this equation that is sometimes used is that the impact of a crisis $=$ the risk (here meaning probability) of a trigger event-such as drought-occurring $x$ the vulnerability of the population to this particular event.
} 
quantified, information-based assessment to identify the best response options in advance; however, much decision-makers may wish to do so. Uncertainty differs from risk in that decisions do not become easier, or more certain, the more information you have. In fact, attempts to collect more and more information can make the situation worse, by causing delay (or 'analysis paralysis') (Quarantelli 1988; Kowlaski-Trakofler and Vaught 2003; Aldunate et al. 2005; Kapucu and Garayev 2011; Comes 2016) or-by focusing decision-makers on what is known, to the exclusion of the (much larger) unknown and unknowable-giving a false sense of certainty (Gigerenzer 2014).

In the world of emergency management, a number of authorities have suggested that this means that approaches to decision-making that have been developed for addressing situations where risks are known, and outcomes can be quantified, may not be appropriate in many contexts. They have suggested instead a variety of other approaches-using intuition, heuristics, and flexible 'try it and see' methods (Flin et al. 1998; Lipshitz et al. 2001; Klein 2009). The survey suggests that there has been much less consideration of these approaches in the humanitarian sector (an exception is Tipper (2016)), although similarities in task and context suggest that these approaches may be worth the consideration. Some of these approaches are considered in the section below.

\section{High levels of stress}

The fact that many humanitarian decisions have important consequences, and that they are often conducted under time pressure and in situations of uncertainty, are described by many of the authors as being an inherent part of the humanitarian context. These conditions can, as we have seen, have direct effects on the processes by which decisions get made: decreasing group participation, or the amount of options that are considered. Stress can also have indirect effects on the decision process, by affecting the decision-maker's emotional and physiological state, which in turn has a 'knock on' effect on the way that the individual makes decisions.

It is important to recognise that different individuals will experience these emotional, cognitive, and physiological effects in different ways (Lu 2017). However, many authors from the emergency management sector have highlighted that stress has, in general, negative effects on decision-making.

Research from emergency management suggests that decision-makers experiencing stress can find it difficult to focus (Aldunate et al. 2005) and will often ignore information and narrow their focus of attention, 'oversimplifying' the situation (Leigh 2016: 5). They may have problems with memory (Weick 1993), become more risk averse (Kowlaski-Trakofler and Vaught 2003), revert to habituated ways of responding (Gralla et al. 2016), and become more reliant on authority figures (Driskell and Salas 1991). All of these behaviours will have (largely) detrimental effects on their ability to make decisionsand particularly the ability to create and choose between a wide range of options. At the same time, the physical element of stress (including effects on sleep, nutrition, and self-care) can affect the ability to make decisions over a period (Zhang et al. 2002; Franklin et al. 2011; Coombs et al. 2016; Comes 2016) and lead to emergency managers 'collaps[ing] from exhaustion or becom[ing] inefficient in their decision-making and other areas of responsibility' (Quarantelli 1988: 380).

However, for all that stress may lead to worse decisions, there are also arguments that stress can improve performance. The 'tunnel vision' that prevents decisionmakers from objectively comparing options can also, according to some authorities, force decision-makers into a better, simplified, and more focused approach (Kowlaski-Trakofler and Vaught 2003; White and Turoff 2010).

\section{The organisational context}

Finally, the literature considered in this survey strongly suggests that individual decision-makers are influenced not only by the nature of the emergency but also by the nature of the organisation in which they work. Heyse (Heyse 2007, 2013) contrasts decision-making in two humanitarian organisations and in doing so demonstrates a relationship between the organisational 'type' (determined by the relative importance of formal structures and of organisational values in the organisation's behaviour) and the way in which decisions are made. Lu (2017), considering emergency management organisations, similarly shows a relationship between organisational type and decisions about strategy in uncertain situations.

A number of authors identify specific elements of the organisation as influencing decision-making. Humanitarian decisions can be guided by organisational strategy (Hayles 2010; Metcalfe et al. 2011; Gralla et al. 2013), by donor requirements (Colombo and Checchi 2018), and by guidelines and standard operating procedures, which allow for 'quick and easy decisions' (Huber and Jennings 2018: 8, see also Knox Clarke 2014). The review of evaluations supported these observations: in 56 of the 369 decisions, the decision-maker(s) considered organisational strategy as an input to the decision, while 59 were recorded as being influenced by donor or funding considerations, and 74 by the structure and procedures of the organisation. If procedures are not used more, it is probably because they are not always relevant to the specific emergency context (Huber and Jennings 2018). This issue is considered by a number of authorities in 
emergency management. Where procedures are used in situations for which they were not designed, they can lead to worse outcomes (Mendonca et al. 2001) and the general consensus in the literature is that they should be used in smaller and more frequently occurring situations (White and Turoff 2010), to support 'stable and wellstructured tasks' (Klein 2009; 28).

Humanitarian organisations also influence decisions through their structure, and in particular, through the degree to which decision-making authority is centralised (Kruke and Olsen 2012) and the quality of their information management and internal communication mechanisms (ibid). Again, these issues have been considered in the emergency management literature, where the authorities considered in this review tended to support more decentralised decision-making authority (Quarantelli 1988; Kowlaski-Trakofler and Vaught 2003; Rodriguez-Espindola et al. 2018).

\section{Making good decisions-approaches for humanitarians \\ Recognising the need to make a decision and knowing which decisions need to be made}

Before any decision is made, the individual or group involved needs to recognise that a decision is required. This may appear obvious, but the literature on humanitarian action provides a number of cases where humanitarian leaders failed to recognise that the situation was one in which decisions needed to be taken. This was the case in Somalia in 2010/11, where the Country Team found it difficult to 'distinguish between routine crisis conditions and those requiring a significant increase in the scale and extent of the humanitarian response', missing the signals that an emergency was occurring (Hobbs et al. 2012: 50, see also Lee et al. 2012). Similar dynamics have been noted in South Sudan (Poole and Primrose 2010) and in the Democratic Republic of Congo (Darcy et al. 2013). Even when it becomes clear that decisions are required, humanitarians-particularly those working in unfamiliar conditions, or with unfamiliar types of emergency-may struggle to identify which decisions need to be made. In the literature, this was identified as a challenge in, among other settings, Darfur (Kruke and Olsen 2012), the Haiti earthquake response (Gralla et al. 2016), the West Africa ebola response (Adams et al. 2015; Murray et al. 2015), and the first months of the humanitarian response to conflict in Syria (UNICEF 2015).

These challenges are a recurrent theme, too, in the emergency management literature (White and Turoff 2010; Kowlaski-Trakofler and Vaught 2003; Gralla et al. 2016): the recognition and formulation of problems is an 'integral part of problem-solving in these settings' (Gralla et al. 2016: 23). The focus on understanding a situation as a key part of the decision-making process owes much to Weick's theory of sensemaking, originally elaborated on the basis of a review of the (disastrous) response to a large-scale fire (Weick 1993) and referred to in several of the articles included in this survey (including Muhren and van der Walle 2009; Comes 2016; Gralla et al. 2016; Bouafia and Khairi Zahari 2017; Lu 2017). In sensemaking theory, individuals and organisations are constantly exposed to a flow of information and events and try to make sense of these events in such a way as to engage in (as well as explain) action. Unexpected events may or may not be noticed and 'extracted' for consideration (Weick et al. 2005). Where they are noticed, they can overwhelm the decision maker, leaving them incapable of deciding on a suitable action. Alternatively, they can be interpreted into 'meaningful patterns that are the basis for decision-making' (Comes 2016: 1).

The experience of the humanitarian system, as outlined in the literature surveyed here, suggests that the humanitarian sensemaking process if often faulty. Important information is not always noticed, because it does not fit the existing understanding of what is happening in a given place and time-as was the case in the Somalia, DRC, and South Sudan cases mentioned above. Where information is noticed, it is often viewed through the prism of organisational mandates, ways of working, and previous decisions (Darcy et al. 2013; Knox Clarke and Darcy 2014; Clarinval and Biller Andorno 2014; Obrecht and Bourne 2018): the 'meaningful patterns' into which new information is organised are largely a construct of existing-potentially misleading-mental models. As a result, humanitarians often suffer from limited situational awareness, particularly when compared with other emergency response systems (Obrecht and Bourne 2018, see, e.g. Salas et al. 1995; Pollock and Coles 2015 for situational awareness in other emergency contexts).

The literature offers a number of potential reasons for the pervasiveness of these mental models and so for the systematic disruption to situational awareness. At a systemic level, an uneven distribution of power means that humanitarians are more sensitive to signals from donors (who are not necessarily well informed about the situation) than they are from the people on the ground (who are) (Steets et al. 2016; Colombo and Checchi 2018). Information may be collected from crisis-affected people, but the information is generally structured according to the models prevalent in organisations-and it is not widely used as a key input to decision-making (Knox Clarke and Darcy 2014; ALNAP 2018). The review of evaluations conducted for this paper confirmed this: in only 15 of 369 decisions were the opinions of crisis affected people mentioned as a significant input to decision-making-both funding and organisational strategy were considered almost four times as often. ${ }^{6}$ 
Similarly, humanitarian monitoring systems tend to focus more on monitoring project outputs (for donors) than on changes in the operational context, or outcomes of humanitarian activities in that context (Warner 2017; Knox Clarke and Darcy 2014; Knox Clarke and Campbell 2015). Within organisations, poor information management and the centralisation of decision-making can mean that cues are not picked up (Kruke and Olsen 2012). Finally, at the level of the individual decisionmaker, stress can lead to unexpected or unwelcome information being ignored, as we have seen above.

Overall, then, the survey suggests that recognition of the need to make decisions, and of the decisions that need to be made, is an area of weakness in humanitarian action connected to poor situational awareness resulting from individual, organisational, and systemic factors.

\section{Making decisions-two differing approaches}

The literature review identified a variety of decisionmaking approaches, most of which can be grouped into two broad categories. The first category is those approaches that follow a rational/analytical decisionmaking logic and focus on making the 'correct' rational choice between a set of options, identifying the option which best fits one's objectives and adds the most value (Choo 2001). The second category covers approaches that can broadly be termed naturalistic decision-making. These focus on making an acceptable decision based on a, generally incomplete, understanding of the current situation and the application of previous experience and intuition. The analytic and naturalistic categories are 'the most important' approaches in discussions of decision-making in emergency management (Bouafia and Khairi Zahari 2017: 4), and a number of articles consider their relative merits in different types of (nonhumanitarian) emergency situation (Flin et al. 1998; Patel et al. 2002; Bouafia and Khairi Zahari 2017).

\section{Rational/analytical decision-making}

Rational/analytical decision-making approaches aim to identify the single best course of action in a situation from among a set of possible options. While the decision-making process will often include steps to identify and frame the problem, the real focus is on identifying a range of options, gathering information to evaluate these options against each other, and then selecting the option that will best address the problem by creating the most 'value' for a given set of inputs (Danielsson and Ohlsson 1999; Lipshitz et al. 2001; Heyse 2013).

Rational/analytical approaches to decision-making are used in many fields of public policy, including healthcare, education, and infrastructure development. The

\footnotetext{
${ }^{6}$ These were mentioned in 59 and 56 decisions, respectively
}

idea of a rational allocation of resources underlies the idea of 'evidence-based' policy: decisions are made through systematic comparison of a series of alternatives (Bradt 2009; Kalra et al. 2014; Obrecht 2017). To allow a valid comparison, these decisions require evidence for the value that will be created by each option (in terms of revenue generated, the number of years of life saved, or the examination results achieved). This generally requires large amounts of information to be collected about the effects of previous interventions and about the current and future circumstances in which the interventions will be made (Lipshitz et al. 2001). The approaches also tend to employ statistical and probabilistic methods (Patel et al. 2002). In some cases, decision-support software, based on the use of mathematical models, are available to calculate the results of various decision options under various circumstances.

There are many advantages to using a rational/analytical approach for decision-making. The first relates to decision quality. The approach is designed to maximise quality: it aims to identify the single best possible decision-that is, the decision that creates the most valuefrom among a number of competing possibilities (Lipshitz et al. 2001; Heyse 2013) Moreover, it does so in a transparent and accountable way (Klein 2009). Typically, the evidence and assumptions behind each decision choice are clearly laid out and can be interrogated by the various stakeholders involved in, or affected by, the decision. Rational approaches to decision-making aim for objectivity and are particularly concerned with overcoming individual bias-to the degree that the study of bias, and of how to overcome bias in the decision-making process, forms an important sub-specialisation of this approach to decision-making (see below). Finally, the transparency required by rational/analytical approaches also make them ideal for group decision-making: the formalised process allows groups to engage by following a single set of rules (Klein 2009). This is important because in humanitarian situations, as in other emergency situations, groups have an important role in effective decision-making (Hochschild 2010; White and Turoff 2010; Kapucu and Garayev 2011; Knox Clarke 2014).

However, as the astute reader will already have recognised, several of the elements that are central to the quality of rational/analytical decisions also make these approaches particularly difficult to use in many humanitarian contexts. As one authority suggests, they are as 'too narrow, too rigid, too consumptive in terms of resources and cognitive capacity, or simply ineffective' (Comes 2016: 7, see also Lipshitz et al. 2001). In particular, they rely on extensive information collection to build a picture about the current and potential future situations. This creates a demand both for time (which may be severely limited) and for cognitive capacity to process 
information (Lipshitz et al. 2001; Patel et al. 2002). Where time or capacity is not available, attempts to gather this information can actually lead to worse decisions (Klein 2009).

More importantly, as pointed out above, the information required to use analytical approaches may simply not be available, even if there were time to obtain it. Where information cannot be obtained, these approaches tend to rely, instead, on the use of assumptions to reduce uncertainty about the future situation (Khorram-Manesh et al. 2016). When making decisions in less dynamic situations, the use of a small number of wellfounded assumptions about the future is understandable (again, this approach is common in public policy, where well-evidenced assumptions about future traffic flows or demographic trends are regularly used in decisions about investment). However, as outlined above, crises are complex. It can be impossible to obtain all the information that would be required to predict the future, and so-as there are so many gaps in the data-forecasting tends to ignore many of the possibilities (RodriguezEspindola et al. 2018) or to rely almost exclusively on assumptions: assumptions which are likely to be wrong (Lu 2017). The result of using rational/analytical approaches in crises can be brittle decisions-ones that are optimal for a particular set of assumptions, but which perform poorly or even disastrously under other assumptions' (Kalra et al. 2014: 8).

A final drawback to the use of rational/analytical approaches-which has been noted beyond the emergency sphere (Leigh 2016) - is the limited attention that these approaches give to understanding and gaining agreement over whether decisions need to be made at all, and what the issue under decision is. As we have seen, the identification and framing of a situation is often a key factor in the quality of emergency decision-making (Klein 2009; Gralla et al. 2016).

And so despite the widely held 'assumption that the best decisions are rational - based on logic and factual information' (Kowlaski-Trakofler and Vaught 2003: 8), many of the sources consulted in this literature review conclude that rational/analytical approaches have limited applicability in 'real world' emergency contexts (see for example Flin et al. 1998; Patel et al. 2002). Indeed, attempts to train emergency professionals in these approaches do not tend to be valued by the trainees (Flin et al. 1996; Flin et al. 1998; Patel et al. 2002). And, while there has been much research into the potential of mathematical modelling and decision-support software to assist humanitarian decision-makers, their utility has been questioned (Besiou et al. 2011) and actual use of these approaches has been limited (Rodriguez-Espindola et al. 2018): overviews of the technology suggest that many of the systems in use appear to focus on allowing decision-makers to access information, rather than on using this information to identify and balance decision options (Ortuño et al. 2013).

At the same time, we should probably question the assumptions made in much of the humanitarian decisionmaking literature that humanitarian contexts are invariably uncertain, stressful, and urgent, making analytical approaches less relevant. This may well be the case in rapid onset crises, particularly in the early stages, but much humanitarian work actually consists of long-term service provision in fairly stable contexts (ALNAP 2015). For these types of operation, rational and analytic approaches can be useful (Flin et al. 1998). Similarly, there may be specific areas of humanitarian action that are particularly well adapted to these approaches: much of the work on decision support, for example, has concentrated on logistics and supply chain management (Rodriguez-Espindola et al. 2018), and in these areas, some computerised systems based on analytical approaches, such as SUMA/LSS, are routinely used (Ortuño et al. 2013). Finally, a number of adaptations to the basic 'rational/analytical' approaches can mitigate some of their limitations for emergency work. For example, decision-makers may generate a number of options, but-rather than choosing one-progress several simultaneously, gradually moving resources to those which appear to be most successful 'on the ground' (Smith and Dowell 2000). Alternatively, they may choose one option but base this choice on the maximal value across the widest number of potential future circumstances, rather than maximal value in one specific set of (assumed) future circumstances (Cosgrave 1996).

\section{Naturalistic decision-making}

The main alternative to rational/analytic approaches to decision-making discussed in the literature is a series of approaches collectively termed 'Naturalistic decisionmaking' or NDM. These approaches were developed, and are often positioned, in opposition to the 'classical' analytic approach outlined above (Patel et al. 2002).

NDM approaches are of particular interest to humanitarians because they emerged largely as a way to approach decision-making in emergency contexts. The approach was first outlined at a 1989 conference of academics and emergency management practitioners (Lipshitz et al. 2001) and is now the predominant decision-making approach in emergency settings including fire, the military, and commercial aviation (Flin et al. 1998; Lipshitz et al. 2001; Klein 2009; Lu 2017) - in other words, situations which are 'marked by time pressure, vague goals, high stakes, team and organization constraints, changing conditions, and varying amounts of experience' (Lu 2017: 20). To date, however, there has been only limited study into the use of NDM in humanitarian contexts. 
Naturalistic decision-making (NDM) has emerged out of studies of practice: from the observation of decisionmaking in emergency situations. As a result, while analytical approaches tend to be prescriptive (identifying what decision-makers should do to maximise value and reduce bias), NDM research has tended to be descriptive, focussing on what experienced decision-makers actually do (Patel et al. 2002; Lu 2017), although a number of authors and researchers have also recommended that it be used more widely in emergency and humanitarian contexts (Klein 2009; Tipper 2016).

The decision-making processes described in the NDM literature are very different from an analytic balancing of various options. Essentially, NDM processes rely on the decision-maker diagnosing the situation in which they find themselves, relating this to previous situations, and then drawing on previous experience to identify a single acceptable and relevant course of action, which is then tested through application. The decision-maker adds the experience of this action, in this situation, to a repertoire that can then be drawn upon in the future (Flin et al. 1998; Lipshitz et al. 2001).

The differences between NDM and rational/analytic approaches are immediately apparent. While the latter focuses largely on the point of making the decision, NDM puts much greater emphasis earlier in the decision process, on understanding the situation and diagnosing what 'type' of situation this is. The actual decision-the action to take-falls out of this process of diagnosis. NDM approaches do not attempt to identify the best possible course of action-rather, they aim to identify a course of action that is 'good enough' because it has been successful in similar situations in the past. And decision-makers using NDM do not identify and choose between a range of options, but instead implement the first action that 'fits'-that will work in that context. If this action is not successful, it may be substituted for another, but these options are considered in sequence, and as needed, rather than being addressed all at the same time.

But the most striking difference between the two approaches lies in the different attitudes they have towards the role of individual, subjective experience in the decision-making process. Rational approaches to decision-making are wary of the role of individual experience, seeing it as being prone to bias. In fact, much of the classical academic work on decision-making (particularly since Kahneman and Tversky published Judgement under Uncertainty in 1974 (Tversky and Kahneman 1974) has focused on how biases negatively impact rational decision-making. 'Bias' is generally understood as cognitive limitations (Roberto 2009) which systematically create a discrepancy between an individual decision-maker's thinking and the rational, 'best' answer (Goncalves 2009; Comes 2016). Biases are understood to be part of the thought processes of all humans (Roberto 2009) and demonstrate themselves when an individual is weighing up possible options-preventing a 'rational' process. ${ }^{7}$ One aim of formalising decision processes, then, is to prevent the process from being affected by bias.

NDM approaches, on the other hand, tend to prioritise individual experience and rely more on intuition than analysis. Decision-makers use their experience and knowledge to engage in 'pattern matching' which allows them to identify the similarities between the current situation and known situation types (Lipshitz et al. 2001; Leigh 2016): in many cases, this seems to be an unconscious, intuitive process. Of course, there are different variations of NDM and some, such as recognitionprimed decision-making, employ the use of analysis to help the decision-maker identify the situation or an appropriate course of action (Smith and Dowell 2000; Klein 2009). But whereas analytical decision-making works to avoid bias, NDM always relies to a degree on heuristics: useful mental shortcuts or 'rules of thumb' which are particular to an individual, based on their own experiences (Goncalves 2009; Gigerenzer 2014; Leigh 2016) and which can enhance the accuracy of decisionmaking (Patel et al. 2002). It is these heuristics that allow an experienced individual to rapidly identify a situation type and to select an appropriate response. The literature review did not throw up any clear or consistent distinction between (bad) 'bias' and (good) 'heuristics'. Anchoring, for example, is described sometimes as a bias and sometimes as a heuristic. The distinction may lie in the degree to which the author thinks that subjective thought is useful in the decision process. Some authorities describe bias and heuristics as two sides of the same coin-biases being the downside of using heuristics (Klein 2009).

Although NDM has evolved from the field of emergency management and is adapted to situations in which both time and information are limited, there are good reasons to be cautious around its application in humanitarian responses. Comes and Goncalves both point to the likelihood that bias will be a problem in humanitarian decision-making-that trusting to 'rules of thumb'

\footnotetext{
7For example, the 'sunk cost fallacy' is a bias whereby, if a cost has already been incurred and cannot be recovered, this cost is given undue recognition when considering future choices (Boardman et al. 2017; Comes 2016; Leigh 2016). The sunk cost fallacy may lead decision-makers to choose to continue with a project which information suggests will not be worth additional investment. While the rational decision might be to cut one's losses and not lose anything further, this bias interferes with rational thought and leads decisionmakers to focus on the cost which has already been spent rather in hopes of recouping their investment, even if this course of action is not likely to maximise their return (Leigh 2016).
} 
may introduce systematic error (Goncalves 2009; Comes 2016). But the most troubling element of NDM, from a humanitarian perspective, is the 'pattern matching' approach, whereby the decision-maker equates the context to a similar situation in the past. There are three main problems with this. Firstly, in order for the decisionmaker to match the present with the past, s/he needs to have good situational awareness-a fairly accurate sense of what is happening in the present. Comparing a situation with one which was not, in fact, similar can be dangerous and lead to very poor decisions (Quarantelli 1988; Leigh 2016). We have already seen that situation awareness is a consistent weakness in humanitarian operations.

Secondly, the decision-maker needs to have past experiences which match the current situation. Intuition and heuristics work well when applied to repetitive tasks/situations (Lipshitz et al. 2001), where the decision-maker has built up enough expertise they can use to create useful models of situations and of relevant responses (Campbell and Knox Clarke 2018: 54). However, if the decision-maker's experience does not match, they may 'focus...on the wrong things' (Klein 2009: 105). Even highly experienced decisionmakers 'may frequently encounter decision situations in which they are novices' (Weingart and Sitkin 1995: 1588). Humanitarian literature and evaluations have identified numerous examples of situations, such as the 2014-2015 Ebola outbreak in West Africa and the European migration 'crisis' resulting from it, where previous experience was not relevant and therefore not useful (ALNAP 2018). In fact, it could be argued that, given the sociological, as well as the technical, nature of humanitarian crisis, the realities of an earthquake, or of displacement in one country will always be different from those in another country. Expatriate workers will find it difficult to effectively apply experience to a new context (Kruke and Olsen 2012). It should not be surprising, then, that a number of evaluations give examples where attempts to apply non-relevant experience has led to poor decision-making (see for example Adams et al. 2015; Aiken and Dewast 2015).

Thirdly, activity selection relies on memories of what has worked in previous, 'matched' situations. However, memory is not always 'an objective record of events' (Leigh 2016: 6) particularly in an emergency (ibid; Weick 1993). As a result, what decision-makers think they 'know' from past experience may not be correct (Goncalves 2009). It is not clear how good humanitarian individuals or organisations are at learning, particularly about operational decisions, where the complexity of the situation may render it impossible to ever know the outcome/impact of a specific decision (Danielsson and Ohlsson 1999).
Beyond the challenges inherent in pattern matching, NDM approaches are also weak on transparency: the decision is made in the 'black box' of the individual decision-maker's mind. Given the importance of accountability to humanitarian activity (Donini and Brown 2014; Knox Clarke 2018) and emergency response more broadly (Lee et al. 2012), this is a concern. As Benini suggests, non-analytical decisions require trust in the organisation (or decision-maker) rather than trust in the numbers (Benini 1997).

And finally, the individualistic nature of NDM approaches would also appear to preclude the use of group decision processes, which are a key element of much successful humanitarian action (Knox Clarke 2014), and to decrease the influence of crisis affected communities on the decision process. However, very little attention has been paid to studying the ways in which groups might use NDM approaches: it is an area where further research is warranted.

It would appear from this review, then, that NDM approaches may have potential for use in humanitarian response-but they are not a 'magic bullet'. However, as is the case with rational/analytical approaches, there is a wide variety of specific methods under the NDM umbrella, and some of these may be more relevant to humanitarian contexts than others. Some variations of $\mathrm{NDM}^{8}$ blend intuitive 'pattern matching' with an element of more structured analysis-and these may allow greater accountability and decrease the risk of decisionmakers falsely assuming that the present is like the past.

\section{Conclusions and next steps}

This survey of humanitarian and emergency literature aims to make tentative hypotheses related to the nature and conditions for success of humanitarian decisionmaking, in the hope that these hypotheses can be tested through further research. It also identifies gaps in our collective understanding of humanitarian decisionmaking where primary research may be required.

On the basis of the literature considered in this survey, we can outline a number of tentative conclusions:

Firstly, that humanitarian decision-makers are in many cases (and particularly in situations which differ from previous experience) failing to identify that decisions and actions are required and/or are failing to identify the priorities for decision-making. This is a result of poor situational awareness, itself largely a result of structural problems in humanitarian organisations and the broader humanitarian system.

${ }^{8}$ For example, variations two and three of recognition-primed decisionmaking which test conclusions by modelling the situation or various courses of action, or the recognition/metacognition model proposed by Cohen et al (1996) which tests the understanding of situation and conclusions using critical thinking. 
Secondly, that a large proportion of humanitarian decisions take place in situations where there is limited time or information to support the decision process; the situation is dynamic and the future uncertain; the decision will have significant consequences on human life; and the decision-maker(s) are likely to experience high levels of stress.

Thirdly, that analytical approaches to decision-making are poorly adapted to these conditions, and that they could be expected to perform poorly in these situations. Conversely, they should perform relatively well in situations where information and time are available and stress is lower.

Fourthly, that 'naturalistic' approaches to decisionmaking are widely used in emergency management organisations in conditions similar to these, may be better adapted to these conditions, and could be expected to perform relatively well under these conditions. However, any effective use of naturalistic approaches by humanitarians will rely on effective situational awareness.

Fifthly, that humanitarian decision-makers should be skilled in using both approaches and adapting their approach to decision-making based on the context in which the decision is being made.

And sixthly, organisations can support effective decision-making by decentralising decision-making authority for operations to those operations and by producing guidance for procedures that are conducted on a regular basis.

It is important to recognise, however, that the literature considered in this survey contained almost no detail on specific humanitarian decision-making processes: how individual decisions were made, under which specific circumstances, and with what results. As a result, these conclusions are based very largely on generalised statements about the context of humanitarian decision-making and on the application of emergency management research to the humanitarian context. We would suggest that these tentative conclusions could form the basis of an important research agenda for humanitarian scholars. Future research could usefully consider the specifics of humanitarian decision-making and interrogate the conclusions above: What proportion of decisions are actually made under conditions of uncertainty, time pressure and stress? How do decision-makers currently identify that decisions are required? How do they make decisions-do they use analytical, naturalistic, or, perhaps, hybrid approaches-and how does the process influence the quality of the decision? More detailed consideration of these issues would, hopefully, lead to better decision-making 'at the sharp end'.

\section{Acknowledgements}

The authors would like to thank Lewis Clough for his assistance during the literature review, and acknowledge the support of the ALNAP secretariat in the development of this article.

\section{Authors' contributions}

LC conducted the initial review of Google Scholar and identified documents for further review on the basis of the inclusion criteria. LC conducted the review of evaluations. PKC coded documents that met the inclusion criteria. PKC identified main points and developed overall structure of the article. LC wrote the first draft of the article. PKC revised the first draft to produce a submission copy of the article. PKC and LC approved the submission copy. PKC revised the submission copy on the basis of reviewer comments and completed responses to comments. PKC and LC approved the revised copy. Both authors read and approved the final manuscript.

\section{Funding}

The work was partially funded by ALNAP/Overseas Development Institute.

\section{Availability of data and materials}

The datasets used and/or analysed during the current study are available from the corresponding author on reasonable request.

\section{Competing interests}

The authors declare that they have no competing interests.

\section{Author details}

${ }^{1}$ Centre for Development and Emergency Practice, Oxford Brookes University, Gipsy Lane Campus, Oxford OX3 OBP, UK. ${ }^{2}$ Action Learning Network for Accountability and Performance, London, UK.

Received: 26 April 2019 Accepted: 12 March 2020

Published online: 15 April 2020

\section{References}

Adams J, Lloyd A, Miller C (2015) The Oxfam ebola response in Liberia and Sierra Leone: an evaluation report for the disasters emergency committee, Oxford

Advisem Services Inc (2016) Final evaluation of the British Red Cross' Haiti Earthquake 2010 Response and Recovery Programme: achievements, challenges and recommendations. British Red Cross, London

Agulhas Applied Knowledge (2015) DFID Syria Crisis Unit: Humanitarian Programme Process Evaluation. Agulhas Applied Knowledge, London

Aiken M, Dewast C (2015) Integrated Urban Shelter and Information Counselling and Legal Assistance (ICLA) Programme. NRC, Oslo

Aldunate RG, Pena-Mora F, Robinson GE (2005) Collaborative distributed decision making for large scale disaster relief operations: drawing analogies from robust natural systems. Complexity 11(2):28-38. https://doi.org/10.1002/cplx.20106

ALNAP (2015) The State of the Humanitarian System. ALNAP Study. ALNAP/ODI, London

ALNAP (2018) The State of the Humanitarian System. ALNAP Study. ALNAP/ODI, London

Ambroso G, Swamy Meier-Ewert G, Parker J, Richardson L (2016) Evaluation of UNHCR's Response to the L3 South Sudan Refugee Crisis In Uganda and Ethiopia. UNHCR Policy Development and Evaluation Service, Geneva

Bandara W, Furtmueller E, Gorbacheva E, Miskon S, Beekhuyzen J (2015) Achieving rigor in literature reviews: insights from qualitative data analysis and tool-support. Commun Assoc Inform Syst 37(8):14-204

Benini AA (1997) Uncertainty and information flows in humanitarian agencies. Disasters 21:335-353

Besiou M, Stapleton O, Van Wassenhove LN (2011) System dynamics for humanitarian operations. J Humanit Logist Supply Chain Manag 1:77-103. https://doi.org/10.1108/20426741111122420

Bouafia M, Khairi Zahari J (2017) Naturalistic decision-making in natural disasters: an overview. J Geography Nat Disasters 7:1

Bradt DA (2009) Evidence based decision making in humanitarian assistance. HPN Network Paper. HPN/ODI, London

Choo CW (2001) Sensemaking, knowledge creation, and decision making organizational knowing as emergent strategy. The strategic management of intellectual capital and organizational knowledge: A collection of readings. Oxford University Press, Oxford 
Clarinval C, Biller-Andorno N (2014) Challenging operations: an ethical framework to assist humanitarian aid workers in their decision-making processes. PLOS Curr Disasters 1. https://doi.org/10.1371/currents.dis. 96bec99f13800a8059bb5b5a82028bbf

Clarke N, Loveless J, Ojok B, Routley S, Vaux T (2015) Report of the inter-agency humanitarian evaluation (IAHE) of the response to the crisis in South Sudan. IAHE, Geneva

Clements A, Thompson E (2009) Making the tough calls: Decision-making in complex humanitarian environments. Humanitarian Exchange 44. HPN/ODI London.

Colombo S, Checchi F (2018) Decision-making in humanitarian crises: politics, and not only evidence, is the problem. Epidemiol Prev 42:214-225

Comes T (2016) Cognitive biases in humanitarian sensemaking and decisionmaking. In: 2016 leee International Multi-Disciplinary Conference on Cognitive Methods in Situation Awareness and Decision Support (cogsima). IEEE, pp 56-62

Coombs D, Soekarjo D, Moossavi N, Bokhari S, Hakimi A, Horst N (2016) Afghanistan-Protracted Relief and Recovery Operation: 200447, assistance to address food insecurity and undernutrition: A mid-term evaluation of WFP's operation (2014-2016). WFP Office of Evaluation

Cosgrave J (1996) Decision making in emergencies. Disaster Prevention Manag Int J 5(4):28-35. https://doi.org/10.1108/09653569610127424

Danielsson M, Ohlsson K (1999) Decision making in emergency management: a survey study. Int J Cogn Ergon 3(2):91-99. https://doi.org/10.1207/ s15327566ijce0302_2

Darcy J (2016a) Evaluation synthesis and gap analysis. Syria Coordinated Accountability and Lessons Learning (CALL) initiative. Steering Group for Inter-Agency Humanitarian Evaluations, New York

Darcy J (2016b) Synthesis of key findings from Inter-Agency Humanitarian Evaluations (IAHEs) of the international responses to crises in the Philippines (Typhoon Haiyan), South Sudan and the Central African Republic. Steering Group for the Inter-Agency Humanitarian Evaluations, New York

Darcy J, Stobaugh H, Walker P, Maxwell D (2013) The use of evidence in humanitarian decision making. Feinstein International Centre: ACAPS, Somerville

Donini A, Brown D (2014) Rhetoric or reality? Putting affected people at the centre of humanitarian action. ALNAP Study. ALNAP/ODI, London

Driskell JE, Salas E (1991) Group decision making under stress. J Appl Psychol 76(3):473-478. https://doi.org/10.1037/0021-9010.76.3.473

Flin R, Strub M, Salas E, \& Martin L (Eds.) (1998) Decision Making under Stress. Emerging Themes and Applications. Routledge, London

Flin R, Slaven G, Stewart K (1996) Emergency decision making in the offshore oil and gas industry. Human Factors. 38:262-277. https://doi.org/10.1177/ 001872089606380207

Franklin A, Liu Y, Li Z, Nguyen V, Johnson TR, Robinson D, Okafor N, King B, Patel VL, Zhang J (2011) Opportunistic decision making and complexity in emergency care.J. Biomed Inform. 44(3):469-476. https://doi.org/10.1016/j.jbi.2011.04.001

Gerdin M, Clarke M, Allen C, Kayabu B, Summerskill W, Devan D, Maclachlan M, Spiegel P, Ghosh A, Zachariah R, Gupta S, Barbour V, Murray V, von Schreeb J (2014) Optimal evidence in difficult settings: improving health interventions and decision making in disasters. PLoS Med 11(4):1-4

Gigerenzer G (2014) Risk Savy - How to make good decisions. Penguin, London

Goncalves P (2009) Heuristics, biases and wrong lessons learned in humanitarian operations 2009. Int Aid Trade Rev:15-17

Gralla E, Goentzel J, de Walle B (2013) Report from the workshop on field-based decision makers' information needs in sudden onset disasters. Digital Humanitarian Network

Gralla E, Goentzel J, Fine C (2016) Problem formulation and solution mechanisms: a behavioral study of humanitarian transportation planning. Prod Oper Manag. 25(1):22-35. https://doi.org/10.1111/poms.12496

Gutjahr W, Nolz P (2010) Multicriteria optimization in humanitarian aid. Eur J Operational Res 252(2016):351-366

Hayles CS (2010) An examination of decision making in post disaster housing reconstruction. Int J Disaster Resil Built Environ 1(1):103-122. https://doi.org/ 10.1108/17595901011026508

Herzing A, van der Wal R (2008) Google Scholar as a new source for citation analysis. Ethics Sci Environ Politics 8:61-73

Heyse L (2007) Choosing the lesser evil. Routledge, London

Heyse L (2013) Tragic choices in humanitarian aid: a framework of organizational determinants of NGO decision making. Voluntas 24:68-92. https://doi.org/10. 1007/s11266-012-9292-y
Hidalgo ST, LaGuardia D, Trudi G, Sole R, Moussa Z, van Dijk J, Merckx P, Zimmer L (2015) Beyond humanitarian assistance? UNHCR and the Response to Syrian Refugees in Jordan and Lebanon, January 2013 - April 2014. UNHCR/ Transtec, Geneva/Brussels

Hobbs C, Gordon M, Bogart B (2012) When business is not as usual: decisionmaking and the humanitarian response to the famine in South Central Somalia. Glob Food Sec 1:50-56

Hochschild F (2010) In and above conflict: a study on leadership in the United Nations, Geneva

Howitt A, Leonard H (2009) Managing crises: responses to large-scale emergencies. CQ Press, Boston

Huber M, Jennings A (2018) Preparing to be unprepared. HIF / ELRHA, London

Kalra N, Halleg AS, Lempert R, Brown C, Fozzard A, Gill S, Shah A (2014) Agreeing on robust decisions new processes for decision making under deep uncertainty. Policy Research Working Paper 6906. The World Bank, Washington DC

Kapucu N, Garayev V (2011) Collaborative decision-making in emergency and disaster management. Int J Public Adm 34:366-375. https://doi.org/10.1080/ 01900692.2011 .561477

Khorram-Manesh A, Berlin J, Carlstrom E (2016) Two validated ways of improving the ability of decision-making in emergencies; results from a literature review. Bull Emerg Trauma 4:186-196

King DJ (2005) Humanitarian knowledge management. 2nd International ISCRAM Conference April 2005, Brussels

Klein G (2009) Streetlights and shadows: searching for the keys to adaptive decision making. MIT Press, Cambridge

Knox Clarke P (2014) Between chaos and control: rethinking operational leadership. ALNAP Study. ALNAP/ODI, London

Knox Clarke P (2018) The state of the humanitarian system. ALNAP Study. ALNAP/ODI, London

Knox Clarke P, Campbell L (2015) Exploring coordination in humanitarian clusters. ALNAP Study. ALNAP/ODI, London

Knox Clarke P, Darcy J (2014) Insufficient evidence? The quality and use of evidence in humanitarian action. ALNAP Study. ALNAP/ODI, London

Kowlaski-Trakofler K, Vaught C (2003) Judgment and decision making under stress: an overview for emergency managers. Int JEmerg Manag 1(3):278-289

Kruke BI, Olsen OE (2012) Knowledge creation and reliable decision- making in complex emergencies. Disasters 36:212-232

Lawday A, Adjibade K, Dahrendorf N, Kubwayezu F, Morinière LC (2016) InterAgency Humanitarian Evaluation (IAHE) of the Response to the Central African Republic's Crisis 2013-2015. IAHE, New York

Lee B, Preston F, Green G (2012) Preparing for high-impact, low-probability events: Lessons from Eyjafjallajökull. The Royal Institute of International Affairs, London, pp 1-62

Leigh M (2016) Emergency planning college occasional papers: critical thinking in crisis management. Emergency Planning College, York

Lipshitz R, Klein G, Orasanu J, Salas E (2001) Taking stock of naturalistic decision making. J Behav Decision Mak 14:331-352

Lu X (2017) Managing uncertainty in crisis. Springer Nature, Singapore

Maxwell D, Stobaugh H, Parker J, Mcglinchy M (2013) Response analysis and response choice in food security crises : a roadmap. ODI, London

Mendonca D, Beroggi GEG, Wallace WA (2001) Decision support for improvisation during emergency response operations. Int JEmerg Manag 1(1):30. https://doi.org/10.1504/IJEM.2001.000507

Metcalfe V, Martin E, Pantuliano S (2011) Risk in humanitarian action : towards a common approach. ODI, London

Muhren J, van der Walle B (2009) Sensemaking and information management in humanitarian disaster response. In: Landgren J, Jul S (eds) Proceedings of the 6th International ISCRAM Conference Gothenburg, Sweden, May 2009

Murray A, Majwa P, Roberton T, Burnham G (2015) Report of the real time evaluation of Ebola control programs in Guinea, Sierra Leone and Liberia. IFRC, Geneva

Obrecht A (2017) Using evidence to allocate humanitarian resources: challenges and opportunities. ALNAP/ODI, London

Obrecht A, Bourne S (2018) Making humanitarian response more flexible. ANLAP Background Paper. ALNAP/ODI, London

Ortuño M, Cristóbal P, Ferrer J, M-C FJ, Muñoz S, Tirado G, Vitorianol B (2013) Decision aid models and systems for humanitarian logistics. A Survey. In: Vitoriano B (ed) Decision Aid Models for Disaster Management and Emergencies. Atlantis Press, Paris 
Oxford Policy Management (2016) Evaluation of the Kenya Hunger Safety Net Programme Phase 2: drought emergency scale-up payments process review. Final Report. Hunger Safety Net Programme, Nairobi

Patel V, Kaufman D, Arocha J (2002) Emerging paradigms of cognition in medical decision-making. JBiomed Inform 35(1):52-75. https://doi.org/10.1016/S15320464(02)00009-6

Pollock K, Coles E (2015) Interoperability: theory \& practice in UK emergency management. Emergency Planning College, York

Poole L, Primrose J (2010) Southern Sudan: funding according to need. Development Initiatives, Wells

Quarantelli EL (1988) Disaster crisis management: a summary of research findings. J ManagStud 25(4):373-385

Quasmi M (2015) Final evaluation report: emergency response operation Pakistan monsoon floods 2014. World in Consulting Limited, Islamabad

Roberto M (2009) The art of critical decision-making. The Teaching Company, Chantilly

Rodriguez-Espindola O, Albores P, Brewster C (2018) Decision-making and operations in disasters: challenges and opportunities. Int J Oper Prod Manag 38(10):1964-1986

Salas E, Prince C, Baker DP, Shrestha L (1995) Situation awareness in team performance: implications for measurement and training. Hum Factors. 37(1): 123-136. https://doi.org/10.1518/001872095779049525

Sanderson D, Rodericks A, Shresta N, Ramalingam B (2015) Nepal earthquake appeal response review. DEC and Humanitarian Coalition (HC), London and Ottowa

Sitkin S, Weingart L (1995) Determinants of risky decision-making behaviour. Academy of Management Journal 14(6) 1573-1592.

Smith W, Dowell J (2000) A case study of co-ordinative decision-making in disaster management. Ergonomics 43(8):1153-1166. https://doi.org/10.1080/ 00140130050084923

Steets J, Binder A, Derzsi-Horvath A, Kruger S, Ruppert L (2016) Drivers and inhibitors of change in the humanitarian system. GPPI, Berlin

Tipper JS (2016) Decision making in disaster response - strategies for frontline humanitarian responders. Relief Advisory International, Auckland

Tversky A, Kahneman D (1974) Judgement under uncertainty:heuristics and biases. Science 185(80):1124-1131. https://doi.org/10.2307/1738360

UNICEF (2015) Evaluation of UNICEF's humanitarian response to the Syria crisis. UNICEF Evaluation Office, New York

Van De Walle B, Comes T (2015) On the nature of information management in complex and natural disasters. Procedia Eng 107:403-411. https://doi.org/10. 1016/j.proeng.2015.06.098

Villa S (2019) Behavioural operations in multi-agent settings and humanitarian operations. In: Villa S, Urrea G, Castenada J, Larsen E (eds) Decision making in humanitarian operations: Strategy, behavior and dynamics. Palgrave Macmillan, Cham

Villa S, Urrea G, Castenada J, Larsen E (2019) Decision making in humanitarian operations: Strategy, behavior and dynamics. Palgrave Macmillan, Cham

Warner AT (2017) What is monitoring in humanitarian action? Describing practice and identifying challenges. ALNAP, London

Weick KE (1993) The collapse of sensemaking in organizations: The Mann Gulch disaster. Adm Sci Quaterly 38(4):628-652. https://doi.org/10.2307/2393339 Organization Science

Weick KE, Sutcliffe K, Obstfeld D (2005) Organizing and the process of sensemaking. Organization Sci 16(4):409-421

Weingart LR, Sitkin SB (1995) Determinants of risky decision-making behavior: a test of the mediating role of risk perceptions and propensity. Acad Manag 38:1573-1592

White C, Turoff M (2010) Factors that influence crisis managers and their decision-making ability during extreme events. Int I Inf Syst Cris Response Manag 2(3):25-35. https://doi.org/10.4018/jiscrm.2010070102

Yu L, Lai KK (2011) A distance-based group decision-making methodology for multi-person multi-criteria emergency decision support. Decis Support Syst 51(2):307-315. https://doi.org/10.1016/j.dss.2010.11.024

Zhang D, Zhou L, Nunamaker JF Jr (2002) A knowledge management framework for the support of decision making in humanitarian assistance/disaster relief. Knowl Inf Syst 4(3):370-385. https://doi.org/10.1007/s101150200012

\section{Publisher's Note}

Springer Nature remains neutral with regard to jurisdictional claims in published maps and institutional affiliations.

\section{Submit your manuscript to a SpringerOpen ${ }^{\circ}$ journal and benefit from:}

- Convenient online submission

- Rigorous peer review

- Open access: articles freely available online

- High visibility within the field

- Retaining the copyright to your article

Submit your next manuscript at $\boldsymbol{\nabla}$ springeropen.com 